\title{
Evaluation of Fragmented Antibody Inhibitory Potency
}

Considerable insight into the structure of antibodies has been gained through the utilization of enzymatic degradation ${ }^{1,2}$. The Fab immunoglobulin fragments, produced by papain digestion, are univalent possessing only one antigen combining site ${ }^{3}$. The Fc fragments do not possess antigen binding capabilities. Since the Fab fragments combine but do not precipitate in the presence of specific antigen, fragmented antibody strength can be assessed only by indirect methods. The present study concerns new approaches in evaluating the inhibitory power of fragmented antibodies. Human chorionic gonadotrophin (HCG) and its homologous antisera were utilized since immunological studies on this system are well established in our laboratory.

Materials and methods. New Zealand white rabbits were immunized with HCG (5000 IU, Parke Davis \& Co.) in complete Freund's adjuvant via multiple site subcutaneous injections ${ }^{4}$. The serum, obtained $6-8$ weeks postimmunization, will be referred to as anti-HCG whole antiserum (WA). In addition, commercial anti-HCG serum $^{5}$ was fractionated with DEAE to obtain the IgG fraction and then digested with papain following the method of PORTER ${ }^{1}$. The digested globulin (Fab and $\mathrm{Fc}$ ) fragments were subjected to Sephadex G-200 gel filtration to remove undigested IgG molecules. Protein concentrations were determined by the Folin-phenol technique ${ }^{6}$. Immunoelectrophoretic analysis revealed the presence of a fast and a slow moving component in the $\gamma$-globulin region. As a control, normal rabbit serum was fractionated to obtain the $\gamma$-globulin fragments and digested in the same manner. The presence of antibody in the degraded product could not be detected by Ouchterlony immunodiffusion.

HCG (Antuitrin-S, $1700 \mathrm{IU} / \mathrm{mg}$, Parke Davis) was labeled with ${ }^{125} \mathrm{I}$ by the method of HuNTER and GREENwood $^{7}$. Sephadex G-100 gel filtration was employed for removal of the free ${ }^{125} \mathrm{I}$ and the resultant product rechromatographed on G-200 in accordance with the method of $\mathrm{BAHL}^{\mathrm{s}}$. The radiohormone contained $2.14 \mu \mathrm{g}$ protein $/ \mathrm{ml}$ and $69.9 \mu \mathrm{C} / \mu \mathrm{g}$ suspended in $0.05 \mathrm{M}$ phosphate buffer stabilized with $0.75 \%$ bovine serum albumin. The free iodine content of the stored radiohormone was monitored periodically by thin layer radiochromatography.

The antigen combining potency of the fragmented antibody (FA) was estimated by a block titration using hemagglutination inhibition (HI). First, varying dilutions of FA were prepared ranging from $1: 3$ to $1: 6144$; then 1 drop $(25 \lambda)$ of WA was added to each dilution. The WA was added at the following dilutions $-1: 300,350,400$, $450,500,550,600$, and 650 . To each of these mixtures was added $25 \lambda$ of sheep tanned red blood cells sensitized to $\mathrm{HCG}$ (Parke Davis, $1700 \mathrm{IU} / \mathrm{mg}$ ) ${ }^{9}$. After $3 \mathrm{~h}$ at room temperature or overnight refrigeration, the results were read and the $50 \%$ dilution endpoint $\left(\mathrm{HI}_{50}\right)$ estimated.

Standard radioprecipitation curves of anti-HCG WA versus ${ }^{125}$ I-HCG were obtained by methods previously described ${ }^{10,11}$. The $\mathrm{HI}_{50}$ endpoint determined the WA concentration for use in radioprecipitation inhibition (RPI). Constant amounts of $\mathrm{WA}^{-\mathrm{HI}_{50}}$ were added to varying dilutions of $\mathrm{FA}$ to determine the power of fragmented anti-HCG to inhibit radioantigen precipitation. To each of the mixtures was added $0.5 \mathrm{~cm}^{3}$ of ${ }^{125} \mathrm{I}-\mathrm{HCG}$ (1:50 dilution) and the mixture incubated at $37^{\circ} \mathrm{C}$ for $1 \mathrm{~h}$, then overnight at $4^{\circ} \mathrm{C} .24 \mathrm{~h}$ later, $50 \lambda$ of non-diluted goat anti-rabbit $\gamma$-globulin was added to each tube. Following incubation and washing, the radioprecipitates were counted in an autowell $\gamma$-counter. Results were plotted as the inverse of the cpm in the sediment versus FA concentration.

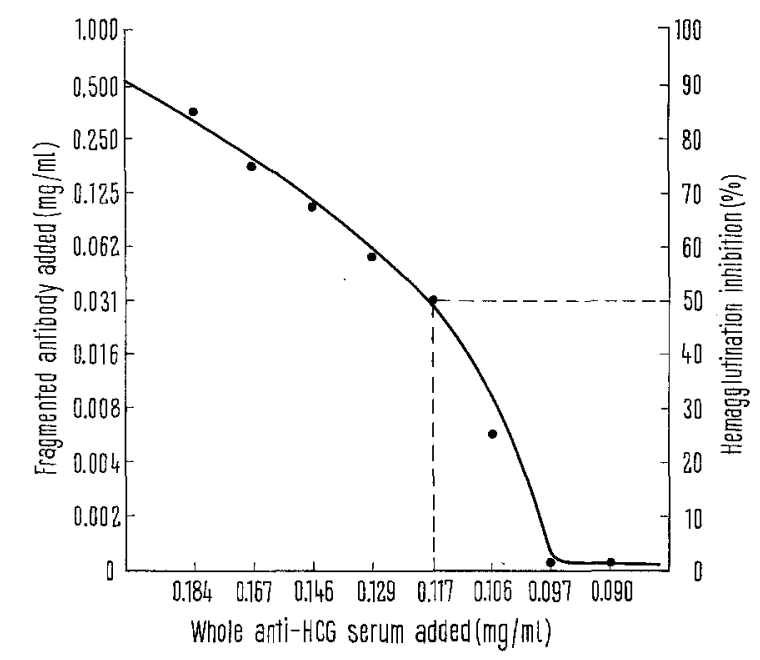

Fig. 1. The inhibitory power of fragmented anti-HCG in competition with antiserum for HCG sensitized red blood cells is demonstrated by hemagglutination inhibition. A ratio of inhibitor (fragmented antibody) to antibody (whole antiserum) of $2.6: 1$ was obtained at the $50 \%$ inhibition point.

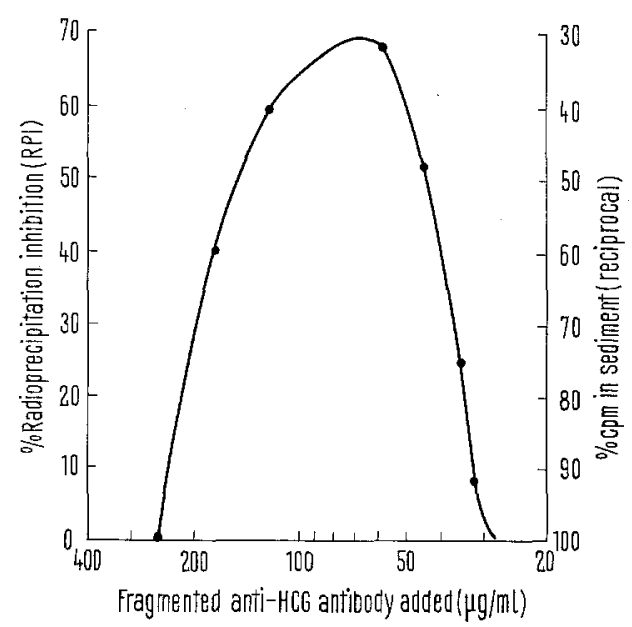

Fig. 2. The power of fragmented anti-HCG to compete with whole antiserum for radioantigen is shown by the percent of radioprecipitation inhibition (RPI). The RPI curve may represent the precipitin curve of the fragmented antibodies when plotted as the inverse of the cpm in the sediment.

I R. R. PORTER, Biochem. J. 73, 119 (1959).

a J. J. Cebra, D. Givol, H. I. Silman and E. Katchalski, J. biol. Chem. 236, 1720 (1961).

3 S. Hsiao and F. W. Putnam, J. biol. Chem. 236, 122 (1961).

4 A. R. Midgeley JR., G. B. Pierce JR. and W. O. Weigle, Proc. Soc. exp. Biol. Med. 108, 85 (1961).

` Hyland Laboratories, Inc., Los Angeles (California, USA).

6 O. H. Lowry, N. J. Rosebrough and R. J. Randall, J. biol. Chem. 193, 265 (1951).

7 W. B. Hunter and F. C. Greenwood, Nature 194, 495 (1962). 8 O. P. BAHL, J. biol. Chem. 244, 567 (1968).

${ }^{\circ} \mathrm{W}$. R. Butr, The Chemisty of the Gonadotrophins (Charles C. Thomas, Springfield, Illinois 1967), p. 107.

10 G. J. GLeich and R. R. Stankievic, Immunochemistry 6, 85 (1969). 11 G. Mize Jewski, Clin. Res. 18, 429 (1970). 
Results and discussion. The quantitative estimates of the inhibitory power of fragmented anti-HCG are shown in Figure 1. The fractionated antibody has a proportionally similar number of antigen binding sites to the intact antiserum except for dilution differences resulting from preparative procedures. Fragmented anti-HCG added to decreasing amounts of WA resulted in the competition curve shown. It can be seen that approximately proportional amounts of FA to WA were needed for inhibition of hemagglutination. The $\mathrm{HI}_{50}$ occurred at a whole antiserum protein concentration of $0.117 \mathrm{mg} / \mathrm{ml} \mathrm{(1:500} \mathrm{dilu-}$ tion). Assuming a minimum of $10 \%$ globulin in the whole antiserum, a ratio of inhibitor to antibody of $2.6: 1$ was obtained at this point.

The $\mathrm{HI}_{50}$ value obtained from Figure 1 dictated the WA concentration $(0.117 \mathrm{mg} / \mathrm{ml})$ for use in radioprecipitation inhibition. The power of fragmented anti-HCG to compete with WA for radioantigen is shown in Figure 2. The inverse of the cpm in the sediment relates the radioprecipitation inhibition throughout a spectrum of FA concentrations titrated against constant amounts of WA. Maximum RPI (69\%) occurred at a FA protein concentration of $60 \mu \mathrm{g} / \mathrm{ml}$ (1:50 dilution). In actuality, the RPI curve represents the precipitin curve of the fragmented antibodies when plotted as the inverse function. The cpm in the sediment are representative of the intact antiserum (WA) interaction with radioantigen since goat anti-rabbit globulin does not readily precipitate the fragments. Cor- respondingly, the $F_{c}$ fragments do not react with the antigen ${ }^{1}$; hence, the curve shown in Figure 2 represents the combined precipitin curves of the 2 Fab fractions.

The inhibitory potency of fragmented antibodies may be titered by hemagglutination inhibition to determine optimum FA: WA ratios and the $\mathrm{HI}_{50}$ index. These data are then employed to measure the immunoprecipitation inhibition capabilities of fragmented antibody. A precipitin curve can be obtained concommittantly with a curve of the percent of inhibition. Precipitin curve analysis reveals the quantities of specific $\mathbf{F A}$ present in the system, the zone of equivalence, areas of antibody and antigen excess, and the molecular combining ratios between antigen and antibody. Thereby, quantitative studies involving fragmented antibodies may be more readily performed.

Zusammentassung. Das Hemmpotential der Antikörperfragmente bei Kaninchen wird mit neuer Methode demonstriert.

\section{G. J. Mizejewski and Jennifer Baron}

University of Michigan Medical Center,

Kresge Medical Research Building,

Ann Arbor (Michigan 48104, USA), and General Medical

Research, Veterans Administration Hospital,

Ann Arbor (Michigan 48105, USA), 22 June 1970.

\section{Dextran Induced Ghanges in the Electrophoretic Mobility of Rat Bone Marrow Erythrocytes}

Large macromolecules like dextran should be expected to influence cellular electrophoretic mobility and this in turn to perhaps produce changes in the cellular metabolic activity ${ }^{1}$. The possibility that cell charge might alter cellular activity has been previously suggested ${ }^{2}$. It was of interest, therefore to determine the influence that various dextran combinations had on cellular electrophoretic mobility, and to determine if electrophoretic mobility could be correlated with an earlier work on oxygen consumption ${ }^{3}$.

Materials and methods. Male Holtzman rats, 42 days old, were used in all experiments. Animals were killed by a sharp blow to the base of the skull and cells were obtained from the bone marrow of the 2 femora and tibiae. 10 animals were used, and 10 measurements of 10 cells were made from each animal.

Dextran solutions of 1,3 , and $5 \%$ were prepared with 39,500 molecular weight dextran (lot 8, 687, Pharmacia, Sweden). One, 3 , and $5 \%$ dextran solutions were prepared using 139,000 mol. wt. clinical grade H dextran (lot H 1158, Pharmachem, Pennsylvania) and 228,000 mol. wt. clinical grade HH dextran (lot HH 82262, Pharmachem). The dextrans were put into solution in Tyrode's medium. The osmolarity of the Tyrode's medium and different dextran solutions was adjusted to $310 \mathrm{mOsm} / \mathrm{l}$ with $\mathrm{NaCl}$ and the $\mathrm{pH}$ adjusted to 7.35 .

Determinations of cellular electrophoretic mobility of mature erythrocytes were made using a microelectrophoresis apparatus modified from that described by BERNSTEIN et al. ${ }^{4}$.

Results. Electrophoretic mobility of mature erythrocytes in the various dextran solutions, isologous serum, and Tyrode's medium is shown in the Figure. Cellular electrophoretic mobility is expressed in relative practical units. Determinations of cellular electrophoretic mobility was limited to mature erythrocytes because this was the only cell type that could be identified with certainty in unstained bone marrow cell preparations using phase and darkfield microscopy.

Erythrocytes of bone marrow suspended in isologous serum had the lowest relative electrophoretic mobility whereas 5\% 39,500 molecular weight dextran medium produced the greatest cellular relative electrophoretic mobility.

Similar electrophoretic mobilities were displayed by cells in tyrodes and the $1 \% 228,000$ molecular weight dextran suspending medium. It was found that as the molecular weight of the dextran suspending medium was increased, the cellular mobility decreased. However, as the concentration of a specific molecular weight dextran was increased the cellular mobility increased.

Discussion. The data reported here indicates that cells incubated in medium containing dextran have a greater cell mobility than do cells incubated in either Tyrode's or serum suspending medium. It is of interest to note that in the artificial media combinations the cell mobility is increased from 2 to 10 times as much as that found in serum. Most probably the cellular electrophoretic mobility of the cells in serum and in the artificial suspending medium is the result of different factors. The factors that need to be considered here are: Agglutination, sedimentation velocity, surface charge, and the dielectric of the suspending medium.

Cellular aggregation occurs with dextrans of 70,000 and greater molecular weight, whereas erythrocyte disaggrega-

1 B. Gardner, Proc. Soc. exp. Biol. Med. 131, 1115 (1969).

2 L. Weiss, North Holland: Amsterdam; J. Wiley; New York (1967).

3 R. M. Gesinski, J. H. Morrison, J. R. Toepfer and C. V. Riley, Experientia 26, 379 (1970)

4 E. F. Bernstein, F. G. Emmines, G. C. Mackey, A. Casteneda and R. L. VARco, Trans. Ass. Art. Int. Organs. 8, 23 (1962). 